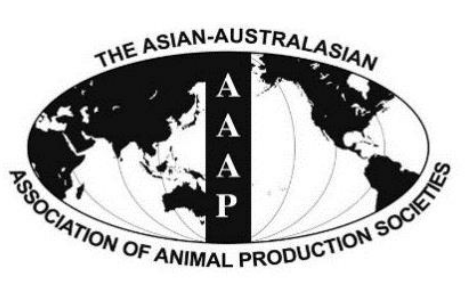

Open Access

\begin{tabular}{c} 
Open Access \\
$\begin{array}{c}\text { Asian Australas. J. Anim. Sci. } \\
\text { Vol. 29, No. } 6 \text { : } 845-854 \text { June } 2016 \\
\text { http://dx.doi.org/10.5713/ajas.15.0784 }\end{array}$ \\
\hline www.ajas.info \\
pISSN 101 1-2367 elSSN 1976-5517
\end{tabular}

\title{
Characteristics and Gel Properties of Gelatin from Goat Skin as Influenced by Alkaline-pretreatment Conditions
}

\author{
Sulaiman Mad-Ali, Soottawat Benjakul*, Thummanoon Prodpran ${ }^{1}$, and Sajid Maqsood ${ }^{2}$ \\ Department of Food Technology, Faculty of Agro-Industry, \\ Prince of Songkla University, Hat Yai, Songkhla 90112, Thailand
}

\begin{abstract}
Characteristics and properties of gelatin from goat skin pretreated with $\mathrm{NaOH}$ solutions $(0.50$ and $0.75 \mathrm{M})$ for various times ( 1 to 4 days) were investigated. All gelatins contained $\alpha$-chains as the predominant component, followed by $\beta$-chain. Gelling and melting temperatures of those gelatins were $23.02^{\circ} \mathrm{C}$ to $24.16^{\circ} \mathrm{C}$ and $33.07^{\circ} \mathrm{C}$ to $34.51^{\circ} \mathrm{C}$, respectively. Gel strength of gelatins increased as $\mathrm{NaOH}$ concentration and pretreatment time increased $(\mathrm{p}<0.05)$. Pretreatment for a longer time yielded gelatin with a decrease in $L^{*}$ value but an increase in $b^{*}$-value. Pretreatment of goat skin using $0.75 \mathrm{M} \mathrm{NaOH}$ for 2 days rendered the highest yield (15.95\%, wet weight basis) as well as high gel strength $(222.42 \mathrm{~g})$, which was higher than bovine gelatin $(199.15 \mathrm{~g})$. Gelatin obtained had the imino acid content of 226 residues/1,000 residues and the gelatin gel had a fine and ordered structure. Therefore, goat skin gelatin could be used as a potential replacer of commercial gelatin. (Key Words: Goat, Gelatin, Skin, Pretreatment, Alkaline, Gel Strength)
\end{abstract}

\section{INTRODUCTION}

Gelatin is the protein obtained by thermal denaturation or partial hydrolysis of collagenous materials (Mohtar et al., 2010). It has many applications in food and non-food industries. In food industry, gelatin is one of the water soluble polymers that can be used to improve stability and consistency of food. For medical and pharmaceutical industries, it can be used to produce soft and hard capsules, wound dressing and adsorbent pads (Widyasari and Rawdkuen, 2014). Gelatin is mainly produced from bovine and porcine skins and demineralized bones (Mohtar et al., 2010). The global demand of gelatin for food and non-food applications was 348.9 kilo tons in 2011 and is expected to

\footnotetext{
* Corresponding Author: Soottawat Benjakul. Tel: +66-74286334, Fax: +66-7455-8866, E-mail: soottawat.b@psu.ac.th

${ }^{1}$ Department of Material Product Technology, Faculty of AgroIndustry, Prince of Songkla University, Hat Yai, Songkhla 90112, Thailand.

${ }^{2}$ Department of Food Science, College of Food and Agriculture, United Arab Emirates University, Al-Ain 15551, United Arab Emirates.

Submitted Sept. 18, 2015; Revised Nov. 30, 2015; Accepted Dec. 6, 2015
}

reach 450.7 kilo tons in 2018 (Sheela, 2014). Different types and sources of materials may yield gelatin with varying properties associated with different amino acid compositions. Gelatin with high imino acids (proline and hydroxyproline) has relatively high gel strength (Cho et al., 2006), due to high hydrogen bonding in gel network (Arnesen and Gildberg, 2007). Gelatin from mammalian skin generally has higher gel strength than fish gelatin (Benjakul et al., 2012). Mammalian gelatin typically has a Bloom value with the range of 200 to $240 \mathrm{~g}$, which is regarded as high Bloom (Karim and Bhat, 2009).

Alkaline pretreatment (liming process) is particularly established for gelatin extraction from mammalian skins and bones, which normally takes a few days to four months, depending on the type and concentration of lime used (Schrieber and Gareis, 2007). The obtained gelatin is considered as "type B" (Hinterwaldner, 1977). Alkaline solution plays an important role in breaking cross-links in the skin matrix stabilized by strong bonds, thereby increasing extraction efficiency (John and Courts, 1977). $\mathrm{NaOH}$ is normally preferred due to its ability to regulate the desired alkalinity and the pretreatment is complete in a very short time (John and Courts, 1977). Nevertheless, the yield 
and gel strength of gelatin are governed by liming conditions. Gel strength and viscosity of gelatin are governed by alkaline type and concentration as well as curing time (Stainsby, 1977; Jamilah et al., 2011). Stronger liming condition normally renders the gelatin with higher viscosity, but generally leads to the lower yield (Schrieber and Gareis, 2007).

Although gelatin has a wide range of applications, distrust and strong concerns still persist among consumers, mainly due to religious sentiments (Sinthusamran et al., 2014). Both Judaism and Islam forbid the consumption of any pork-derived products, while Hindus do not consume cow-derived products (Badii and Howell, 2003). Avian influenza is also a concern in a poultry-related product. Therefore, the extraction of gelatin from alternative mammals, especially by-products from goat slaughtering, e.g. skin or bone, should be taken into consideration.

Goat is one of the economically important animals raised in Thailand for their meat and milk. The number of goats increased from 130,904 head in 1998 to 491,779 head in 2012 and is still gradually increasing (Department of Livestock Development, 2014). The number of goats increased annually since their meat has become promising for consumption, especially for Muslims. When goats are slaughtered, by-products including skin accounts for $6.4 \%$ to $11.6 \%$ (based on the body weight) (Warmington and Kirton, 1990). The skin can be used as an alternative raw material for gelatin extraction. However, little information regarding gelatin from goat skin has been reported. Extraction under the optimized condition is a means to produce gelatin from goat skin with high yield and quality equivalent or superior to commercially available gelatin. The present study aimed to investigate the impact of alkaline pretreatment conditions on characteristics and gel properties of gelatin from goat skin obtained from a slaughter house in the southern part of Thailand.

\section{MATERIALS AND METHODS}

\section{Chemicals}

All chemicals were of analytical grade. Sodium dodecyl sulfate (SDS), Coomassie blue R-250 and $N, N, N^{\prime}, N^{\prime}-$ tetramethylethylenediamine were procured from Bio-Rad Laboratories (Hercules, CA, USA). High-molecular-weight markers were obtained from GE Healthcare UK Limited (Buckinghamshire, UK). Food grade bovine bone gelatin with the bloom strength of 150 to $250 \mathrm{~g}$ was purchased from Halagel (Thailand) Co., Ltd. (Bangkok, Thailand).

\section{Collection and preparation of goat skin}

Skins from Anglo-Nubian goats with an age of approximately 2 years were collected from a local slaughter house in Chana district, Songkhla province, Thailand. Seven kilograms of goat skins were randomly taken from three goats, pooled and used as the composite sample. The skins were packed in polyethylene bag, embedded in an insulated box containing ice (a skin/ice ratio of 1:2, w/w) and within $2 \mathrm{~h}$ transported to the Department of Food Technology, Prince of Songkla University. Upon arrival, the skins were cleaned and washed with running water $\left(26^{\circ} \mathrm{C}\right.$ to $\left.28^{\circ} \mathrm{C}\right)$. Prepared skins were then cut into small pieces $\left(2.5 \times 2.5 \mathrm{~cm}^{2}\right)$ using knives, placed in polyethylene bags and stored at $-20^{\circ} \mathrm{C}$ until use. The storage time was not longer than 2 months.

\section{Alkaline-pretreatment of goat skin}

Prepared skins were soaked in $\mathrm{NaOH}$ solution $(0.50 \mathrm{M}$ and $0.75 \mathrm{M})$ with a skin/solution of $1: 10(\mathrm{w} / \mathrm{v})$ at $25^{\circ} \mathrm{C}$. During pretreatment, the mixtures were stirred manually twice a day. Pretreatment was performed for 1, 2, 3, and 4 days. At every sampling time, the solutions were removed and replaced by the same volume of fresh solution. The treated skins were washed with running water until the $\mathrm{pH}$ of wash water became neutral or slightly alkaline. During pretreatment and washing, hair and other non-collagen materials released from the skin were removed. All pretreated skins were subjected to gelatin extraction.

\section{Extraction of gelatin}

To extract gelatin, the pretreated skins were placed in distilled water at $60^{\circ} \mathrm{C}$ with a skin/water ratio of $1: 10(\mathrm{w} / \mathrm{v})$ in a temperature-controlled water bath (W350, Memmert, Schwabach, Germany) for $5 \mathrm{~h}$ with a continuous stirring at a speed of $150 \mathrm{rpm}$ using an overhead stirrer equipped with a propeller (RW 20.n, IKA-Werke GmbH \& CO.KG, Staufen, Germany). The mixture was then filtered using two layers of cheesecloth. The filtrate was further filtered using a Whatman No. 4 filter paper (Whatman International, Ltd., Maidstone, England) with the aid of JEIO Model VE-11 electric aspirator (JEIO TECH, Seoul, Korea). The resultant filtrate was freeze-dried using a ScanvacModel Coolsafe 55 freeze dryer (Coolsafe, Lynge, Denmark). All gelatins were subjected to analyses.

\section{Analyses}

Yield and recovery: The yield of gelatin was calculated by the following equations:

$$
\text { Yield }(\%)=\frac{\text { Weight of dried gelatin }(\mathrm{g}) \times 100}{\text { Weight of initial skin }(\mathrm{g})}
$$

$$
\begin{aligned}
& \text { Recovery }(\%) \\
& =[\text { hydroxyproline content of filtrate }(\mathrm{g} / \mathrm{mL}) \\
& \quad \times \text { volume of filtrate }(\mathrm{mL})] \\
& \quad /[\text { hydroxyproline content of initial skin }(\mathrm{g} / \mathrm{g}) \\
& \quad \times \text { weight of initial skin }(\mathrm{g})] \times 100
\end{aligned}
$$


Hydroxyproline content was determined according to the method of Bergman and Loxley (1963).

Sodium dodecyl sulfate-polyacrylamide gel electrophoresis: Sodium dodecyl sulfate-polyacrylamide gel electrophoresis (SDS-PAGE) was performed following the method of Laemmli (1970). Gelatin samples were dissolved in $5 \% \mathrm{SDS}$ and the mixtures were incubated at $85^{\circ} \mathrm{C}$ for $1 \mathrm{~h}$. Solubilized samples were mixed at $1: 1(\mathrm{v} / \mathrm{v})$ ratio with the sample buffer $(0.5 \mathrm{M}$ Tris $\mathrm{HCl}, \mathrm{pH}$ 6.8. containing 4\% SDS and $20 \%$ glycerol). The mixtures were boiled in boiling water for $2 \mathrm{~min}$. Samples (15 $\mu \mathrm{g}$ protein) were loaded onto polyacrylamide gels comprising a $7.5 \%$ running gel and a $4 \%$ stacking gel and subjected to electrophoresis. Gels were stained with $0.05 \%(\mathrm{w} / \mathrm{v})$ Coomassie blue R-250 in $15 \%$ $(\mathrm{v} / \mathrm{v})$ methanol and $5 \%(\mathrm{v} / \mathrm{v})$ acetic acid and destained with $30 \%(\mathrm{v} / \mathrm{v})$ methanol and $10 \%$ acetic acid. High molecular weight (MW) markers were used for estimation of MW.

Fourier transform infrared spectroscopic analysis: Fourier transform infrared (FTIR) spectra of gelatin samples were obtained using a FTIR spectrometer (EQUINOX 55, Bruker, Ettlingen, Germany) equipped with a deuterated l-alanine tri-glycine sulfate detector. The horizontal attenuated total reflectance accessory was mounted into the sample compartment. The internal reflection crystal (Pike Technologies, Madison, WI, USA), made of zinc selenide, had a $45^{\circ}$ angle of incidence to the infrared (IR) beam. Spectra were acquired at a resolution of $4 \mathrm{~cm}^{-1}$ and the measurement range was 4,000 to $650 \mathrm{~cm}^{-1}$ (mid-IR region) at room temperature. Automatic signals were collected in 32 scans at a resolution of $4 \mathrm{~cm}^{-1}$ and were rationed against a background spectrum recorded from the clean empty cell at $25^{\circ} \mathrm{C}$. Analysis of spectral data was carried out using the OPUS 3.0 data collection software programme (Bruker, Germany).

Determination of gelling and melting temperatures: Gelling and melting temperatures of gelatin samples were measured following the method of Boran et al. (2010) using a controlled stress rheometer (RheoStress RS 75, HAAKE, Karlsruhe, Germany). Gelatin solution (6.67\%, w/v) was prepared in the same manner as described previously. The solution was preheated at $35^{\circ} \mathrm{C}$ for $30 \mathrm{~min}$. The measuring geometry used was $3.5 \mathrm{~cm}$ parallel plate and the gap was set at $1.0 \mathrm{~mm}$. The measurement was performed at a scan rate of $0.5^{\circ} \mathrm{C} / \mathrm{min}$, frequency of $1 \mathrm{~Hz}$, oscillating applied stress of $3 \mathrm{~Pa}$ during cooling from $50^{\circ} \mathrm{C}$ to $5^{\circ} \mathrm{C}$ and heating from $5^{\circ} \mathrm{C}$ to $50^{\circ} \mathrm{C}$. The gelling and melting temperatures were designated, where tan $\delta$ became 1 or $\delta$ was $45^{\circ}$.

Determination of gel strength: Gelatin gel was prepared as per the method of Kittiphattanabawon et al. (2010). Gelatin was dissolved in distilled water $\left(60^{\circ} \mathrm{C}\right)$ to obtain a final concentration of $6.67 \%(\mathrm{w} / \mathrm{v})$. The solution was stirred until gelatin was solubilized completely and transferred to a cylindrical mold with $3 \mathrm{~cm}$ diameter and $2.5 \mathrm{~cm}$ height. The solution was refrigerated at $4^{\circ} \mathrm{C}$ for $18 \mathrm{~h}$ prior to analysis.

Gel strength was determined at $8^{\circ} \mathrm{C}$ to $10^{\circ} \mathrm{C}$ using a texture analyzer (Stable Micro System, Surrey, UK) with a load cell of $5 \mathrm{~kg}$, cross-head speed of $1 \mathrm{~mm} / \mathrm{s}$, equipped with a $1.27 \mathrm{~cm}$ diameter flat-faced cylindrical Teflon plunger. The maximum force (grams) was recorded when the plunger had penetrated $4 \mathrm{~mm}$ into the gelatin gels.

Microstructure analysis of gelatin gel: Microstructure of gelatin gel was visualized using a scanning electron microscope (standard error of the mean). Gelatin gels having a thickness of 2 to $3 \mathrm{~mm}$ were fixed with $2.5 \%(\mathrm{v} / \mathrm{v})$ glutaraldehyde in $0.2 \mathrm{M}$ phosphate buffer ( $\mathrm{pH} \mathrm{7.2)}$ ) for $12 \mathrm{~h}$. The samples were then rinsed with distilled water for $1 \mathrm{~h}$ and dehydrated in ethanol with a serial concentration of $50 \%, 70 \%, 80 \%, 90 \%$, and $100 \%$ (v/v). The samples were subjected to critical point drying. Dried samples were mounted on a bronze stub and sputter-coated with gold (Sputter coater SPI-Module, West Chester, PA, USA). The specimens were observed with a scanning electron microscope (JEOL JSM-5800 LV, Tokyo, Japan) at an acceleration voltage of $20 \mathrm{kV}$.

Determination of color of gelatin gel: The color of gelatin gels $(6.67 \% \mathrm{w} / \mathrm{v})$ was measured by a Hunter lab colorimeter (Color Flex, Hunter Lab Inc., Reston, VA, USA). $L^{*}, a^{*}$, and $b^{*}$ values indicating lightness/brightness, redness/greenness, and yellowness/blueness, respectively, were recorded. The colorimeter was warmed up for $10 \mathrm{~min}$ and calibrated with a white standard. Total difference in color $\left(\Delta E^{*}\right)$ was calculated according to the following equation (Gennadios et al., 1996):

$$
\Delta E^{*}=\sqrt{\left(\Delta L^{*}\right)^{2}+\left(\Delta a^{*}\right)^{2}+\left(\Delta b^{*}\right)^{2}}
$$

where $\Delta L^{*}, \Delta a^{*}$, and $\Delta b^{*}$ are the differences between the corresponding color parameter of the sample and that of white standard $\left(L^{*}=93.63, a^{*}=-0.94\right.$, and $\left.b^{*}=0.40\right)$.

Amino acid analysis: Amino acid composition of the selected gelatin sample was analyzed according to the method of Nagarajan et al. (2012) with a slight modification. The sample was hydrolyzed under reduced pressure in $4 \mathrm{M}$ methanesulphonic acid containing $0.2 \% \quad(\mathrm{v} / \mathrm{v}) \quad 3-2(2-$ aminoethyl) indole at $115^{\circ} \mathrm{C}$ for $24 \mathrm{~h}$. The hydrolysate was neutralized with $3.5 \mathrm{M} \mathrm{NaOH}$ and diluted with $0.2 \mathrm{M}$ citrate buffer ( $\mathrm{pH}$ 2.2). An aliquot of $0.04 \mathrm{~mL}$ was applied to an amino acid analyzer (MLC-703; Atto Co., Tokyo, Japan).

\section{Statistical analysis}

All experiments were run in triplicate using three different lots of skins. Data were subjected to analysis of variance and mean comparisons were carried out using the Duncan's multiple range test (Steel et al., 1980). For pair 
comparison, T-test was used. Statistical analysis was performed using the statistical Package for Social Sciences (SPSS for windows: SPSS Inc., Chicago, IL, USA).

\section{RESULTS AND DISCUSSION}

\section{Yield of extraction}

The yields and recovery of gelatin extracted from goat skin pretreated using various $\mathrm{NaOH}$ concentrations are shown in Table 1. Gelatin from skin pretreated with $\mathrm{NaOH}$ solution at both concentrations $(0.5 \mathrm{M}$ or $0.75 \mathrm{M})$ had an increasing yield as the pretreatment times increased $(\mathrm{p}<0.05)$. Nevertheless, gelatin from skin pretreated with $0.5 \mathrm{M} \mathrm{NaOH}$ for 4 days had the lower yield, compared with those pretreated for 2 and 3 days $(\mathrm{p}<0.05)$. On the other hand, skins were not swollen when they were pretreated with $0.5 \mathrm{M} \mathrm{NaOH}$ for only 1 day (data not shown). For gelatin extracted from the skins pretreated using $0.75 \mathrm{M}$ $\mathrm{NaOH}$, a lower yield was obtained when pretreatment time was longer than 2 days (data not shown). Under the harsh alkaline condition, the repulsion between protein chains in the skin matrix became more pronounced. As a result, solubilization was augmented and the loss of gelatin was obtained. The use of weak alkaline condition for a short time was not sufficient to destroy the cross-links in the skin matrix. In general, the higher yield was obtained when the skins were pretreated with $0.75 \mathrm{M} \mathrm{NaOH}$, in comparison with that of $0.5 \mathrm{M} \mathrm{NaOH}$. Yields of $11.38 \%$ to $13.23 \%$ and $11.60 \%$ to $15.95 \%$ (on wet weight basis) were found for gelatin extracted from skin pretreated with $\mathrm{NaOH}$ at concentrations of $0.5 \mathrm{M}$ and $0.75 \mathrm{M}$, respectively. The recovery of gelatin from skin pretreated with $\mathrm{NaOH}$ at 0.5 $\mathrm{M}$ and $0.75 \mathrm{M}$ were $22.50 \%$ to $30.26 \%$ and $27.40 \%$ to $34.16 \%$, respectively. The highest yield from goat skin $(15.95 \%)$ was obtained when the pretreatment of skin was carried out using $0.75 \mathrm{M} \mathrm{NaOH}$ for 2 days $(\mathrm{p}<0.05)$. Jamilah et al. (2011) reported that yield of gelatin (wet weight basis) from skins of red tilapia, walking catfish and striped catfish were $12.92,13.06$ and 11.17 , respectively, when alkaline pretreatment was used before extraction. Cho et al. (2006) reported that the highest extraction yield
$(16.80 \%)$ of gelatin from skate skin was found when the skin was pretreated with $1.5 \%$ calcium hydroxide $\left(\mathrm{Ca}(\mathrm{OH})_{2}\right)$ for 2 days. The different yields might be due to different skin matrixs between mammals and fish as well as the gelatin extraction process including pretreatment (Kittiphattanabawon et al., 2010; Nagarajan et al., 2012). Goat skin has a complex structure with strong fibrils, compared with those from fish skin. As a result, harsher pretreatment conditions were required. The result suggested that higher alkaline concentration used for pretreatment more likely destroyed the covalent bond stabilizing the cross-links in the skin matrix. As a consequence, intermolecular cross-links between collagen fibrils were destabilized and could be extracted into the medium with ease, leading to the higher yield (Hinterwaldner, 1977). With longer pretreatment time, those bonds were more disrupted, releasing more free $\alpha$-chains or $\beta$-chain from the skin complex during extraction.

\section{Protein patterns}

Protein patterns of gelatin from goat skin pretreated with $\mathrm{NaOH}$ at different concentrations for various times are illustrated in Figure 1. All gelatin samples contained $\alpha$ chains as the major component. $\beta$-chain was also found in all samples. MWs of $\alpha_{1}$ - and $\alpha_{2}$-chains were estimated to be 131 and $124 \mathrm{kDa}$, respectively. B-chain, a dimer, had MW of $216 \mathrm{kDa}$. For all gelatin samples, no marked differences in protein patterns were noticeable. The result indicated that $\alpha$-chains and $\beta$-chain were not degraded by pretreatment conditions. However, proteins with MW greater than $\beta$ chain were slightly higher in band intensity as the gelatin was extracted from goat skin pretreated with $\mathrm{NaOH}$ for a longer time, particularly with $0.75 \mathrm{M} \mathrm{NaOH}$. For alkaline pretreatment of channel catfish skin using $1 \mathrm{~g} / \mathrm{L}\left(\mathrm{Ca}(\mathrm{OH})_{2}\right)$ for $76 \mathrm{~h}, \alpha$-chains were more degraded (Liu et al., 2008). Generally, gelatins with higher content of $\alpha$-chains showed the better functional properties including gelling, emulsifying and foaming properties (Gómez-Guillén et al., 2002). Thus, the components including $\alpha$-chains and $\beta$ chains of gelatin from goat skin were quite tolerant to alkaline pretreatment, compared with other species,

Table 1. Extraction yield, recovery, gel strength and gel color of gelatin from goat skin pretreated with $\mathrm{NaOH}$ at different concentrations for various times

\begin{tabular}{|c|c|c|c|c|c|c|c|c|}
\hline \multirow{2}{*}{$\begin{array}{l}\mathrm{NaOH} \\
\text { concentration }(\mathrm{M})\end{array}$} & \multirow{2}{*}{$\begin{array}{l}\text { Time } \\
\text { (d) }\end{array}$} & \multirow{2}{*}{$\begin{array}{c}\text { Yield } \\
\text { (\% wet weight basis) }\end{array}$} & \multirow{2}{*}{$\begin{array}{c}\text { Recovery } \\
(\%)\end{array}$} & \multirow{2}{*}{$\begin{array}{l}\text { Gel strength } \\
(\mathrm{g})\end{array}$} & \multicolumn{4}{|c|}{ Color value } \\
\hline & & & & & $L^{*}$ & $a^{*}$ & $b^{*}$ & $\Delta E^{*}$ \\
\hline \multirow[t]{3}{*}{$\overline{0.5}$} & 2 & $13.23 \pm 0.17^{\mathrm{Ab}}$ & $30.26 \pm 0.50^{\mathrm{Ac}}$ & $211.71 \pm 3.79^{\mathrm{Aab}}$ & $18.17 \pm 0.50^{\mathrm{Ab}}$ & $2.89 \pm 0.65^{\mathrm{Aa}}$ & $7.30 \pm 0.19^{\mathrm{Aa}}$ & $75.85 \pm 0.53^{\mathrm{Aa}}$ \\
\hline & 3 & $14.79 \pm 0.25^{\mathrm{Bc}}$ & \pm \pm 0.5 & $216.46 \pm 1.83^{\mathrm{Ab}}$ & $17.64 \pm 0.48^{\mathrm{ABb}}$ & $2.80 \pm 0.72^{\mathrm{Aa}}$ & $8.04 \pm 0.38^{\mathrm{ABc}}$ & $76.43 \pm 0.45^{\mathrm{Bb}}$ \\
\hline & 4 & $11.38 \pm 0.52^{\mathrm{Ca}}$ & $22.50 \pm 0.37^{\mathrm{Ca}}$ & $229.51 \pm 2.68^{\mathrm{Be}}$ & $16.88 \pm 0.24^{\mathrm{Ba}}$ & $2.30 \pm 0.19^{\mathrm{Aa}}$ & $8.56 \pm 0.54^{\mathrm{Bc}}$ & $77.22 \pm 0.30^{\mathrm{Bb}}$ \\
\hline \multirow[t]{2}{*}{0.75} & 1 & $11.60 \pm 0.11^{\mathrm{Aa}}$ & $27.40 \pm 0.24^{\mathrm{Ab}}$ & $209.18 \pm 3.05^{\mathrm{Aa}}$ & $17.83 \pm 0.20^{\mathrm{Ab}}$ & $2.88 \pm 0.12^{\mathrm{Aa}}$ & $7.16 \pm 0.06^{\mathrm{Aa}}$ & $76.16 \pm 0.20^{\mathrm{Aa}}$ \\
\hline & 2 & $15.95 \pm 0.08^{\mathrm{Bd}}$ & $34.16 \pm 0.28^{\mathrm{Be}}$ & $222.42 \pm 2.87^{\mathrm{Bc}}$ & $16.958 \pm 0.30^{\mathrm{Ba}}$ & $2.81 \pm 0.25^{\mathrm{Aa}}$ & $7.44 \pm 0.08^{\mathrm{Bb}}$ & $77.05 \pm 0.29^{\mathrm{Bb}}$ \\
\hline
\end{tabular}

Values are presented as mean \pm standard deviation $(\mathrm{n}=3)$.

Different uppercase letters within the same column under the same $\mathrm{NaOH}$ concentration indicate significant differences (p<0.05). Different lowercase letters within the same column indicate significant differences $(\mathrm{p}<0.05)$. 


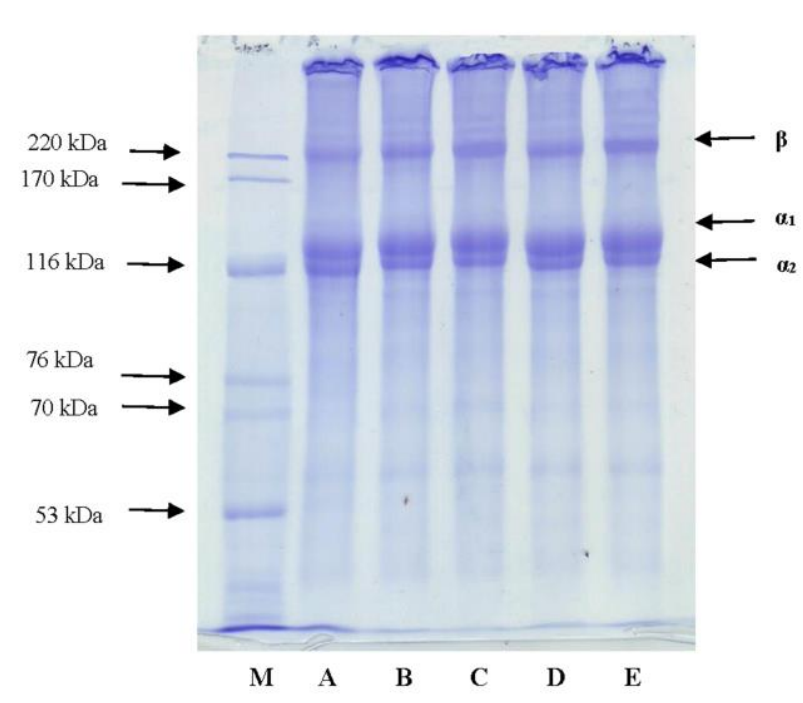

Figure 1. Sodium dodecyl sulfate-polyacrylamide gel electrophoresis (SDS-PAGE) patterns of gelatin from goat skin pretreated with $\mathrm{NaOH}$ at different concentrations for various times. $\mathrm{M}$ denotes high molecular weight markers. A, B, C: gelatin from goat skin pretreated with $0.5 \mathrm{M} \mathrm{NaOH}$ for 2, 3, and 4 days, respectively and $\mathrm{D}$, E: gelatin from goat skin pretreated with $0.75 \mathrm{M} \mathrm{NaOH}$ for 1 and 2 days, respectively.

particularly fish.

\section{Fourier transform infrared spectra}

FTIR spectra of gelatin from the skins of goat pretreated with $\mathrm{NaOH}$ under different conditions are shown in Figure 2. In general, all gelatins showed similar spectra. Amide I band of gelatin pretreated with $\mathrm{NaOH}$ at concentrations of 0.5 and $0.75 \mathrm{M}$ for various times appeared at 1,630.42 to $1634.21 \mathrm{~cm}^{-1}$ and 1631.50 to $1638.30 \mathrm{~cm}^{-1}$, respectively. The amide $\mathrm{I}$ vibration mode is primarily a $\mathrm{C}=\mathrm{O}$ stretching vibration coupled to contributions from the $\mathrm{C}-\mathrm{N}$ stretch, $\mathrm{CCN}$ deformation and in-plane $\mathrm{N}-\mathrm{H}$ bending modes (Bandekar, 1992). The absorption in the amide I region is probably the most useful for infrared spectroscopic analysis of the secondary structure of proteins (Nagarajan et al., 2012). The absorption peak at amide I was characteristic for the coil structure of gelatin (Nagarajan et al., 2012). When the wavenumber shifts to the lower frequencies, those functional groups might undergo interaction with some reactive groups. For amide II, it results from an out-ofphase combination of $\mathrm{C}-\mathrm{N}$ stretch and in-plane $\mathrm{N}-\mathrm{H}$ deformation modes of the peptide group (Bandekar, 1992). Amide II bands of all gelatin samples were noticeable at the wavenumbers of $1,535.04$ to $1,541.03 \mathrm{~cm}^{-1}$ and $1,527.25$ to $1,543.27 \mathrm{~cm}^{-1}$ for gelatin from skin pretreated with $0.5 \mathrm{M}$ and $0.75 \mathrm{M} \mathrm{NaOH}$, respectively. It was observed that they shifted to lower wavenumber in gelatin from skin pretreated for a longer time. The amide III bands of all gelatin samples were observed at wavenumbers of $1,234.30$ to

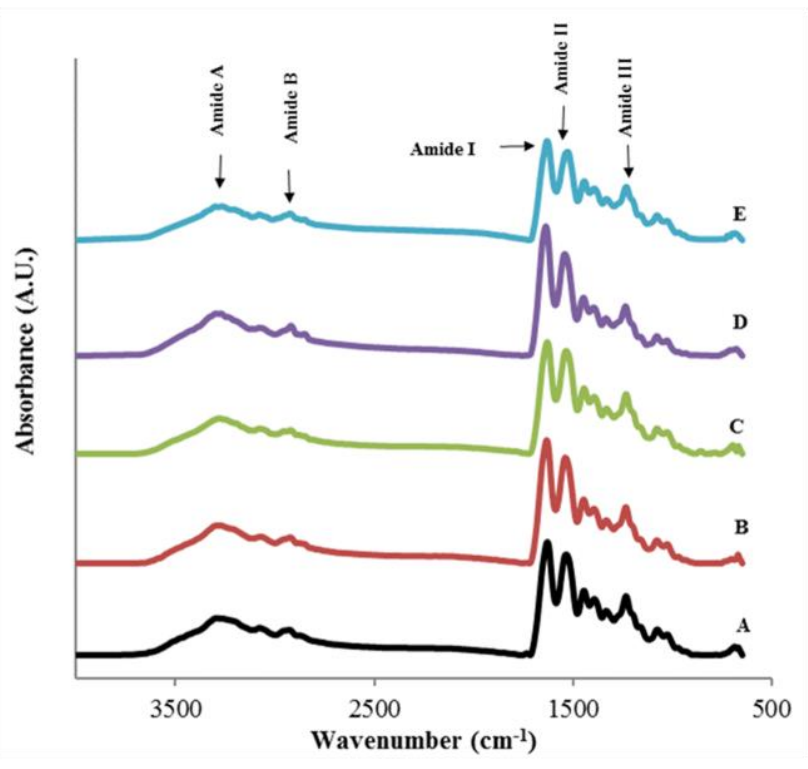

Figure 2. Fourier transform infrared (FTIR) spectra of gelatin from goat skin pretreated with $\mathrm{NaOH}$ at different concentrations for various times. A, B, C: gelatin from goat skin pretreated with $0.5 \mathrm{M} \mathrm{NaOH}$ for 2, 3, and 4 days, respectively and D, E: gelatin from goat skin pretreated with $0.75 \mathrm{M} \mathrm{NaOH}$ for 1 and 2 days, respectively.

1,237.11 $\mathrm{cm}^{-1}$, which indicated the disorder in gelatin molecules and were more likely associated with loss of triple helix state (Friess and Lee, 1996). The amide III band represents the combination peaks between $\mathrm{C}-\mathrm{N}$ stretching vibrations and $\mathrm{N}-\mathrm{H}$ deformation from amide linkages as well as absorptions taking place from wagging vibrations from $\mathrm{CH}_{2}$ groups of glycine backbone and proline sidechains (Nagarajan et al., 2012). However, no remarkable differences were observed in amide III among samples. During extraction at high temperature, hydrogen bonds stabilizing triple helix were destroyed, leading to amorphous structure.

The amide A band of gelatin from skin pretreated with $\mathrm{NaOH}$ at concentrations of 0.5 and $0.75 \mathrm{M}$ for various times was found at $3,280.70$ to $3,295.72 \mathrm{~cm}^{-1}$ and $3,268.89$ to $3,272.38 \mathrm{~cm}^{-1}$, respectively, associated with stretching vibrations of $\mathrm{N}-\mathrm{H}$ group coupled with hydrogen bonding. Basically, a free N-H stretching vibration is found in the range of 3,400 to $3,440 \mathrm{~cm}^{-1}$. The position of this band shifts to lower frequencies because the N-H group of a peptide is involved in a hydrogen bond (Nagarajan et al., 2012). Gelatin from skin pretreated with $\mathrm{NaOH}$ at the same concentration for longer time showed the lower amplitude than other gelatin samples. Coincidentally, the shift to lower wavenumber was found in gelatin samples extracted from skin pretreated for a longer time. This might be due to the free amino group released undergoing the Maillard reaction to a higher extent. This could enhance the yellow color in the sample. The amide $\mathrm{B}$ band of gelatin from skin 
pretreated with 0.5 and $0.75 \mathrm{M} \mathrm{NaOH}$ for various times was found at 2,922.60 to $2,928.28 \mathrm{~cm}^{-1}$ and $2,920.31$ to $2,925.38$ $\mathrm{cm}^{-1}$, respectively, corresponding to the asymmetric stretching vibration of $=\mathrm{C}-\mathrm{H}$ as well as $\mathrm{NH}_{3}{ }^{+}$(Friess and Lee, 1996). Among all samples, gelatin pretreated for longer time had the lowest wavenumber of amide-B peak. This suggested the interaction of free amino groups with other, especially, carbonyl compounds via glycation. Thus, the secondary structure and functional group of gelatins derived from skin of goat were affected by alkaline pretreatment.

\section{Gelling and melting temperatures}

The changes in the phase angle $(\delta)$ of gelatin solutions during cooling $\left(50^{\circ} \mathrm{C}\right.$ to $\left.5^{\circ} \mathrm{C}\right)$ and subsequent heating $\left(5^{\circ} \mathrm{C}\right.$ to $50^{\circ} \mathrm{C}$ ) are illustrated in Figure $3 \mathrm{~A}$ and $3 \mathrm{~B}$, respectively. All gelatin samples with different pretreatment conditions formed a gel in the range of $23.02^{\circ} \mathrm{C}$ to $24.16^{\circ} \mathrm{C}$. This was regarded as the sharp decrease and rapid transition in phase angle during cooling, due to the increase in amount of energy that is elastically stored in storage modulus $\left(G^{\prime}\right)$ (Kasankala et al., 2007). It was found that gelling
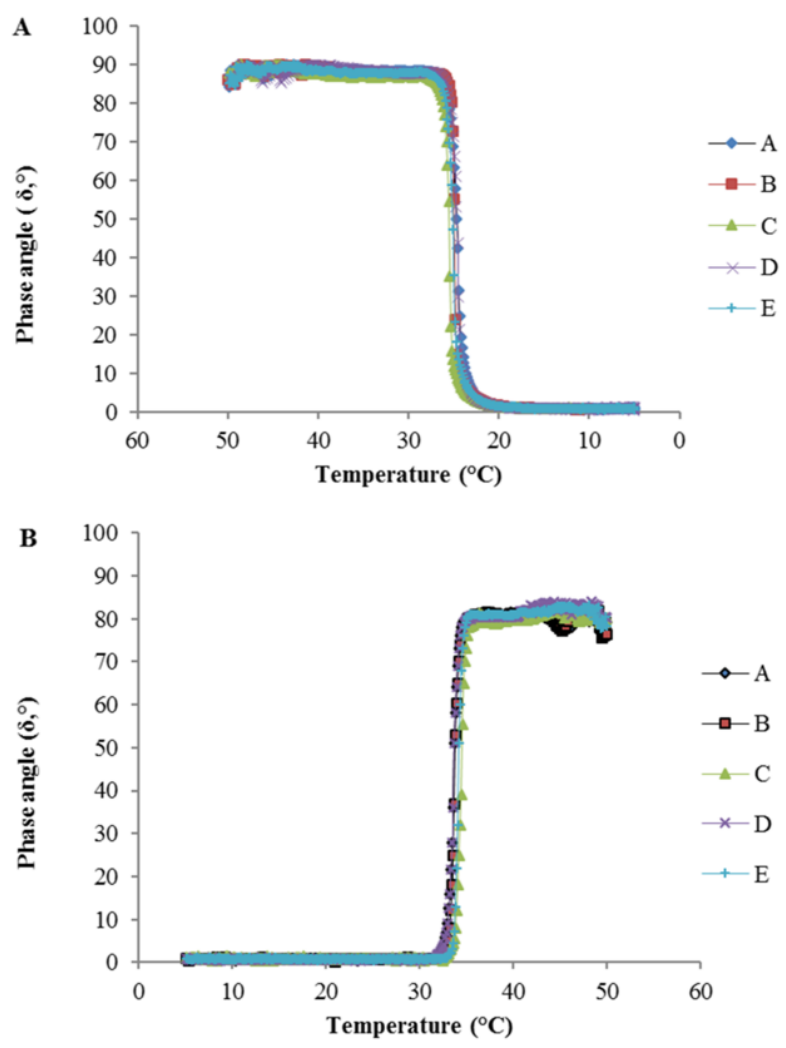

Figure 3. Changes in phase angle $\left(\delta,^{\circ}\right)$ of gelatin solution $(6.67 \%$, w/v) from goat skin pretreated with $\mathrm{NaOH}$ at different concentrations for various times during cooling (A) and subsequent heating (B). A, B, C: gelatin from goat skin pretreated with $0.5 \mathrm{M} \mathrm{NaOH}$ for 2,3 , and 4 days, respectively and D, E: gelatin from goat skin pretreated with $0.75 \mathrm{M} \mathrm{NaOH}$ for 1 and 2 days, respectively. temperature of gelatins from skin pretreated with the same $\mathrm{NaOH}$ concentration increased non-significantly with increasing pretreatment time $(\mathrm{p}>0.05)$. However, gelling temperature was not much affected by the pretreatment conditions used in the present study. The gelling temperature of gelatin from goat skin was higher than those of gelatins from skin of bigeye snapper $\left(10.0^{\circ} \mathrm{C}\right.$ ) (Binsi et al., 2009) and silver carp $\left(18.7^{\circ} \mathrm{C}\right)$ (Boran et al., 2010). Moreover, gelling temperature was also higher than that of other mammal gelatin such as bovine $\left(21.7^{\circ} \mathrm{C}\right)$ (Kasankala et al., 2007). Karim and Bhat (2009) reported that melting point and gelling point are governed mainly by the amino acid composition (pro+hyp content), molecular weight distribution and also the ratio of $\alpha / \beta$ chains in the gelatin.

Melting points of gelatins from goat skin with various pretreatments were found in the range of $33.07^{\circ} \mathrm{C}$ to $34.51^{\circ} \mathrm{C}$, which were higher than those reported for gelatin from bigeye snapper skin $\left(16.8^{\circ} \mathrm{C}\right)$ (Binsi et al., 2009), silver carp skin $\left(27.1^{\circ} \mathrm{C}\right)$, porcine $\left(31.5^{\circ} \mathrm{C}\right)$ and bovine $\left(30^{\circ} \mathrm{C}\right)$ (Kasankala et al., 2007). The high melting point in this study might be associated with the high content of imino acids (Pro and Hyp) (Kasankala et al., 2007). The proline plays a crucial role in boosting the formation of polyproline II helix (Ross-Murphy, 1992). Thermal stability of gelatin gel is directly related with Pro-rich regions in gelatin molecules (Gómez-Guillén et al., 2002). Apart from imino acid content, the melting point of gelatin also increases with increasing MW (Jamilah and Harvinder, 2002). With higher melting temperature, gel could be retained for a longer time, thereby producing a better mouth feel when consumed. The gelling and melting temperatures of gelatin depend on species used as raw material, which may have different living environments and habitat temperatures (Gómez-Guillén et al., 2002). Age of animal in conjunction with cross-link formation is another important factor affecting the gelling and melting behavior of gelatin (Hinterwaldner, 1977).

\section{Gel strength of gelatin gel}

Gel strength of gelatin gels from goat skin pretreated with $\mathrm{NaOH}$ solution under varying conditions is shown in Table 1. Gel strength is one of the most important functional properties of gelatins. The highest gel strength $(229.52 \mathrm{~g})$ was found in gelatin from skin pretreated with $0.5 \mathrm{M} \mathrm{NaOH}$ for 4 days $(\mathrm{p}<0.05)$, followed by that extracted from skin pretreated with $0.75 \mathrm{M} \mathrm{NaOH}$ for 2 days. Gel strength of gelatin gels more likely increased as the pretreatment times increased $(p<0.05)$. The amount of $\beta$ and $\gamma$-components of gelatin was one of the factors governing gelation of gelatin (Taheri et al., 2009). However, no marked differences in $\alpha$ - and $\beta$-components of all gelatins were observed (Figure 1). It was observed that protein bands with MW higher than $\beta$-chain were slightly 
higher in intensity, when gelatin was extracted from skin pretreated using $\mathrm{NaOH}$ for a longer time. Those components might favor the network formation and strengthen the 3-dimentional network of gel. Goat skin gelatin had the higher gel strength (209.18 to $229.51 \mathrm{~g}$ ) than bovine gelatin $(199.15 \mathrm{~g})$ (data not shown) $(\mathrm{p}<0.05)$. Gelatin with different gel strength from various sources including brownbanded bamboo shark and blacktip shark (206 to 214 g) (Kittiphattanabawon et al., 2010), seabass (282 to $369 \mathrm{~g}$ ) (Sinthusamran et al., 2014) and chicken feet (79 to $185 \mathrm{~g}$ ) (Widyasari and Rawdkuen, 2014) were reported. Pretreatment condition and type of raw material have an influence on the chemical composition of gelatin, which directly affects the functional properties, especially gelation (Benjakul et al., 2012). Molecular weight distribution was considered as a factor determining the gelling property of gelatin (Gómez-Guillén et al., 2002). Thus, pretreatment process associated with both $\mathrm{NaOH}$ concentration and pretreatment time affected gel strength of gelatin.

\section{Microstructures of gelatin gels}

The microstructures of gelatin gels from goat skin with different pretreatment conditions are illustrated in Figure 4. Generally, the conformation and chain length of proteins in gel matrix directly determine the gel strength of gelatin (Benjakul et al., 2009). With the same $\mathrm{NaOH}$ concentration, gelatin gel showed a finer network with very small voids as the pretreatment time increased. Among all samples, gelatin from skin pretreated with $0.5 \mathrm{M} \mathrm{NaOH}$ for 4 days and that extracted from skin pretreated using $0.75 \mathrm{M} \mathrm{NaOH}$ for 2 days had the fine structure. Nevertheless, the former showed larger strands, which were more resistant to force applied. This was evidenced by the higher gel strength (Table 1). Conversely, the larger voids were found in gel of gelatin from skin pretreated for the shorter pretreatment time. The coarser gel structure of gelatin from skin pretreated for shorter time was in accordance with the lower gel strength (Table 1). The coarser gel network tended to have the lower gel strength and was easy to disrupt. It is well known that the distribution of $\alpha-, \beta$-, and $\gamma$-chains is an important factor affecting property of gelatin (Sinthusamran et al., 2014). In addition, hydroxyproline is involved in gel formation of nucleation zones via hydrogen bonding through its -OH group (Kittiphattanabawon et al., 2010). Yang et al. (2008) reported that the gelatin gel network was governed by pretreatment conditions. Therefore, the arrangement and association of gelatin molecules in the gel matrix directly contributed to gel strength of gelatin from goat skin with alkaline pretreatment.

\section{Color of gelatin gel}

Color of gelatin gel from goat skin with different pretreatment conditions expressed as $L^{*}, a^{*}$, and $b^{*}$ are
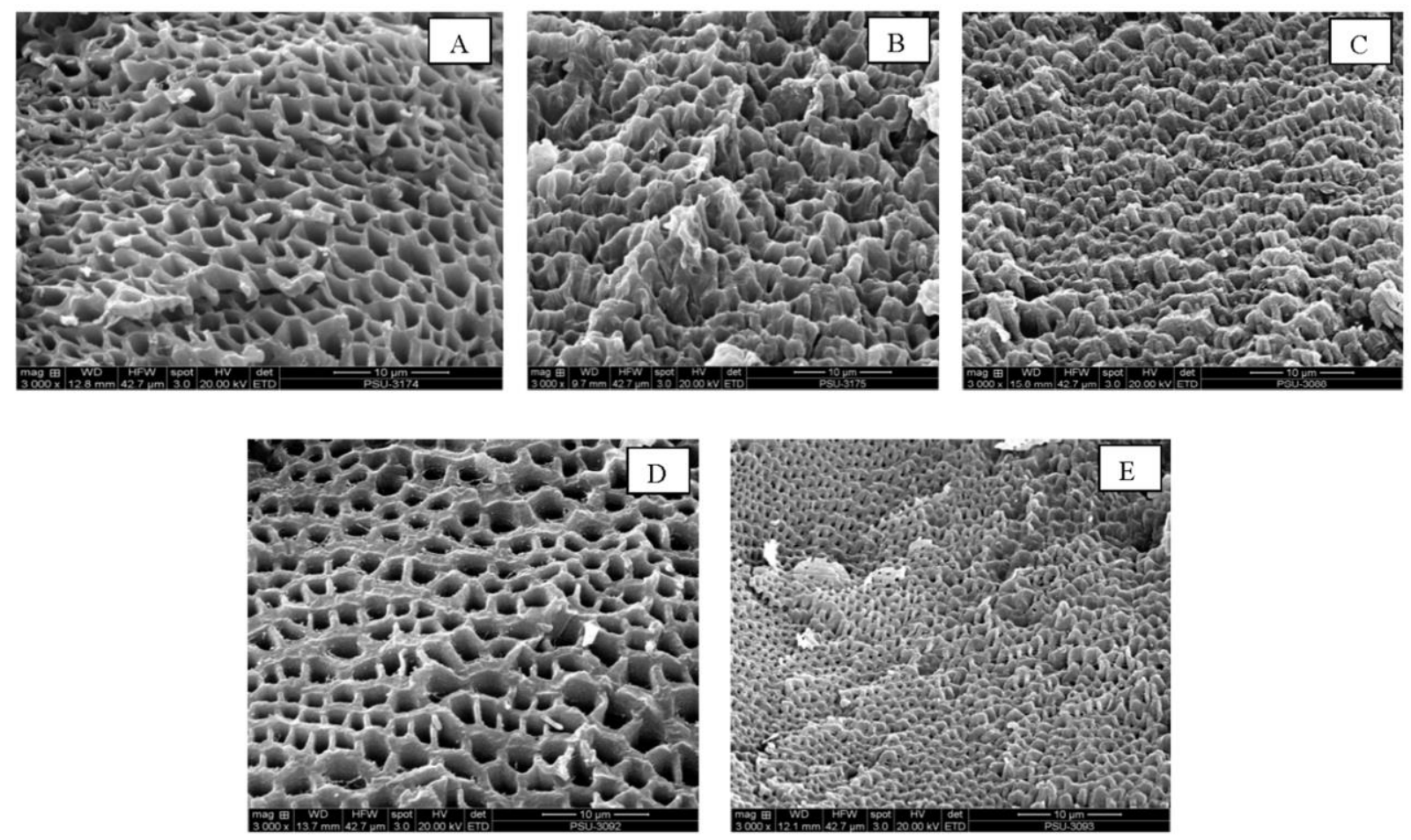

Figure 4. Microstructures of gelatin gel from goat skin pretreated with $\mathrm{NaOH}$ at different concentrations for various times. Magnification: 3,000×. A, B, C: gelatin from goat skin pretreated with $0.5 \mathrm{M} \mathrm{NaOH}$ for 2, 3, and 4 days, respectively and D, E: gelatin from goat skin pretreated with $0.75 \mathrm{M} \mathrm{NaOH}$ for 1 and 2 days, respectively. 
shown in Table 1 . Lightness ( $L^{*}$-values) of gelatin gel decreased, while $b^{*}$-value increased when the pretreatment time increased $(\mathrm{p}<0.05)$. Nevertheless, no differences in $a^{*}$ value were noticeable among all samples $(p>0.05)$. The increases in yellowness $(b *$-value) of gelatin gel from skin pretreated for a longer time were in agreement with the shift of Amide A and B to the lower wavenumber (Figure 2). It has been known that Maillard reaction is favored at alkaline condition (Lertittikul et al., 2007). With the longer pretreatment time, the reaction might occur to a higher extent. Among all gelatin samples, that from the skin pretreated at lower $\mathrm{NaOH}$ concentration $(0.5 \mathrm{M})$ for the shortest time (2 days) showed the lowest total difference in color value $\left(\Delta E^{*}\right)(75.85)$ with the highest lightness $\left(L^{*}\right.$ values). These results showed that the pretreatment conditions affected gel color of gelatin from goat skin.

\section{Amino acid composition}

Amino acid composition of gelatin from goat skin pretreated with $0.75 \mathrm{M} \mathrm{NaOH}$ for 2 days, rendering the highest yield and gel strength, is shown in Table 2. Glycine was the major amino acid (329 residues/1,000 residues). Gelatin had very low contents of cysteine ( 1 residues $/ 1,000$ residues), tyrosine (3 residues/1,000 residues) and histidine

Table 2. Amino acid compositions of gelatin from goat skin pretreated with $0.75 \mathrm{M} \mathrm{NaOH}$ for 2 days, compared with those of bovine and porcine gelatins

\begin{tabular}{lccc}
\hline \multirow{2}{*}{ Amino acids } & \multicolumn{3}{c}{ Residue/1,000 residues } \\
\cline { 2 - 4 } & Goat gelatin & $\begin{array}{c}\text { Bovine } \\
\text { gelatin* }\end{array}$ & $\begin{array}{c}\text { Porcine } \\
\text { gelatin** }\end{array}$ \\
\hline Aspartic acid/asparagine & 45 & 44 & 54 \\
Threonine & 18 & 17 & 25 \\
Serine & 32 & 29 & 41 \\
Glutamic acid/glutamine & 73 & 74 & 81 \\
Glycine & 329 & 341 & 328 \\
Alanine & 110 & 115 & 114 \\
Cysteine & 1 & 0 & 0 \\
Valine & 20 & 21 & 18 \\
Methionine & 6 & 5 & 12 \\
Isoleucine & 11 & 11 & 9 \\
Leucine & 25 & 25 & 20 \\
Tyrosine & 3 & 1 & 2 \\
Phenylalanine & 13 & 12 & 14 \\
Hydroxylysine & 6 & 7 & 8 \\
Lysine & 28 & 26 & 22 \\
Histidine & 5 & 5 & 8 \\
Arginine & 49 & 48 & 45 \\
Hydroxyproline & 99 & 96 & 70 \\
Proline & 127 & 123 & 129 \\
Total & 1,000 & 1,000 & 1,000 \\
Imino acids & 226 & 219 & 199 \\
\hline & & & \\
Jelloulet. & 19 & \\
\hline
\end{tabular}

(5 residues/1,000 residues). Glycine generally occurs every third position of $\alpha$-chain and represents nearly one third of total residues except for 14 amino acids from $\mathrm{N}$-termini and for 10 amino acids from C-termini (Benjakul et al., 2012). For imino acids, gelatin had proline and hydroxyproline of 127 and 99 residues/1,000 residues, respectively. The imino acid content of gelatin from goat skin (226 residues/1,000 residues) was higher than that reported for gelatin from silver carp waste (197 residues/1,000 residues) (Tavakolipour, 2011), grey triggerfish skin (176 residues/1,000 residues) (Jellouli et al., 2011), salmon skin (166 residues/1,000 residues) and cod skin (154 residues/1,000 residues) (Arnesen and Gildberg, 2007). Moreover, it was higher than that found in bovine gelatin (219 residues/1,000 residues) (Jellouli et al., 2011) and porcine skin gelatin (199 residues/1,000 residues) (Tavakolipour, 2011). Gelatin with higher content of hydroxyproline possessed viscoelastic properties of gelatin and ability to develop the strong gel structure (Benjakul et al., 2009). OH groups of hydroxyproline might be involved in hydrogen bondings with adjacent chains (Kittiphattanabawon et al., 2010). This could strengthen gel network of gelatin. Additionally, alanine (110 residues/1,000 residues and glutamic acid/glutamine (73 residues/1,000 residues) were also found at high content. Therefore, amino acid composition could be another factor determining the properties of gelatin from goat skin.

\section{CONCLUSIONS}

The skin of goat could be a promising source of gelatin. Pretreatment condition affected the characteristic and properties of gelatin. Gelatin from goat skin contained $\alpha$ chains as the major constituent. All gelatins from different pretreatment conditions showed higher gel strength than that of commercial bovine gelatin. The optimal pretreatment condition for gelatin extraction from goat skin was the use of $0.75 \mathrm{M} \mathrm{NaOH}$ for 2 days.

\section{CONFLICT OF INTEREST}

We certify that there is no conflict of interest with any financial organization regarding the material discussed in the manuscript.

\section{ACKNOWLEDGMENTS}

The authors would like to express their sincere thanks to the PSU Halal Institute (Contract No. AGR01H57), Hat Yai campus and the Graduate School of Prince of Songkla University, for the financial support. 


\section{REFERENCES}

Arnesen, J. A. and A. Gildberg. 2007. Extraction and characterisation of gelatine from Atlantic salmon (Salmo salar) skin. Bioresour. Technol. 98:53-57.

Badii, F. and N. K. Howell. 2003. Elucidation of the effect of formaldehyde and lipids on frozen stored cod collagen by FTraman spectroscopy and differential scanning calorimetry. J. Agric. Food Chem. 51:1440-1446.

Bandekar, J. 1992. Amide modes and protein conformation. BBAProtein Struct. M. 1120:123-143.

Benjakul, S., P. Kittiphattanabawon, and J. M. Regenstein. 2012. Fish gelatin. In: Food Biochemistry and Food (Eds. B. K. Simpson, L. M. L. Nollet, and F. Toldrae). John Wiley \& Sons Inc., Ames, IA, USA. pp. 388-405.

Benjakul, S., K. Oungbho, W. Visessanguan, Y. Thiansilakul, and S. Roytrakul. 2009. Characteristics of gelatin from the skins of bigeye snapper, Priacanthus tayenus and Priacanthus macracanthus. Food Chem. 116:445-451.

Bergman, I. and R. Loxley. 1963. Two improved and simplified methods for the spectrophotometric determination of hydroxyproline. Anal. Chem. 35:1961-1965.

Binsi, P. K., B. A. Shamasundar, A. O. Dileep, F. Badii, and N. K. Howell. 2009. Rheological and functional properties of gelatin from the skin of Bigeye snapper (Priacanthus hamrur) fish: Influence of gelatin on the gel-forming ability of fish mince. Food Hydrocoll. 23:132-145.

Boran, G., S. J. Mulvaney, and J. M. Regenstein. 2010. Rheological properties of gelatin from silver carp skin compared to commercially available gelatins from different sources. J. Food Sci. 75:565-571.

Cho, S.-H., M. L. Jahncke, K.-B. Chin, and J.-B. Eun. 2006. The effect of processing conditions on the properties of gelatin from skate (Raja Kenojei) skins. Food Hydrocoll. 20:810-816.

Development of Livestock Developmengt, Goat farming statistic in Thailand since 1998 to 2012. 2014. http://www.dld.go.th /ict/stat_web/yearly/yearly56/ Accessed October 5, 2014.

Friess, W. and G. Lee. 1996. Basic thermoanalytical studies of insoluble collagen matrices. Biomaterials 17:2289-2294.

Gennadios, A., C. L. Weller, M. A. Hanna, and G. W. Froning. 1996. Mechanical and barrier properties of egg albumen films. J. Food Sci. 61:585-589.

Gómez-Guillén, M. C., J. Turnay, M. D. Fernández-Díaz, N. Ulmo, M. A. Lizarbe, and P. Montero. 2002. Structural and physical properties of gelatin extracted from different marine species: A comparative study. Food Hydrocoll. 16:25-34.

Hinterwaldner, R. 1977. Technology of gelatin manufacture. In: The Science and Technology of Gelatin (Eds. A. G. Ward and A. Courts). Academic Press, London, UK. pp. 315-364.

Jamilah, B. and K. G. Harvinder. 2002. Properties of gelatins from skins of fish-black tilapia (Oreochromis mossambicus) and red tilapia (Oreochromis nilotica). Food Chem. 77:81-84.

Jamilah, B., K. W. Tan, M. R. Umi Hartina, and A. Azizah. 2011. Gelatins from three cultured freshwater fish skins obtained by liming process. Food Hydrocoll. 25:1256-1260.

Jellouli, K., R. Balti, A. Bougatef, N. Hmidet, A. Barkia, and M. Nasri. 2011. Chemical composition and characteristics of skin gelatin from grey triggerfish (Balistes capriscus). LWT-Food
Sci. Technol. 44:1965-1970.

John, P. and A. Courts. 1977. Relationship between collagen and gelatin. In: The science and technology of gelatin (Eds. A. G. Ward and A. Courts). Academic Press, London, UK. pp. 138168

Karim, A. A. and R. Bhat. 2009. Fish gelatin: properties, challenges, and prospects as an alternative to mammalian gelatins. Food Hydrocoll. 23:563-576.

Kasankala, L. M., Y. Xue, Y. Weilong, S. D. Hong, and Q. He. 2007. Optimization of gelatine extraction from grass carp (Catenopharyngodon idella) fish skin by response surface methodology. Bioresour. Technol. 98:3338-3343.

Kittiphattanabawon, P., S. Benjakul, W. Visessanguan, and F. Shahidi. 2010. Comparative study on characteristics of gelatin from the skins of brownbanded bamboo shark and blacktip shark as affected by extraction conditions. Food Hydrocoll. 24:164-171.

Laemmli, U. K. 1970. Cleavage of structural proteins during the assembly of the head of bacteriophage T4. Nature 227:680-685.

Lertittikul, W., S. Benjakul, and M. Tanaka. 2007. Characteristics and antioxidative activity of Maillard reaction products from a porcine plasma protein-glucose model system as influenced by pH. Food Chem. 100:669-677.

Liu, H. Y., D. Li, and S. D. Guo. 2008. Extraction and properties of gelatin from channel catfish (Ietalurus punetaus) skin. LWT-Food Sci. Technol. 41:414-419.

Mohtar, N. F., C. Perera, and S.-Y. Quek. 2010. Optimisation of gelatine extraction from hoki (Macruronus novaezelandiae) skins and measurement of gel strength and SDS-PAGE. Food Chem. 122:307-313.

Nagarajan, M., S. Benjakul, T. Prodpran, P. Songtipya, and H. Kishimura. 2012. Characteristics and functional properties of gelatin from splendid squid (Loligo formosana) skin as affected by extraction temperatures. Food Hydrocoll. 29:389397.

Ross-Murphy, S. B. 1992. Structure and rheology of gelatin gels: Recent progress. Polymer 33:2622-2627.

Schrieber, R. and H. Gareis. 2007. Gelatine handbook, theory and industrial practice. Wiley-VCH $\mathrm{GmbH} \&$ Co., Weinheim, Germany. pp. 63-71.

Sheela, A. K. 2014. Gelatin Market - global industry analysis, size, share, growth, trends and fsorecast, 2012-2018. http://www.transparencymarketresearch.com/gelatin.html Accessed October 3, 2014.

Sinthusamran, S., S. Benjakul, and H. Kishimura. 2014. Characteristics and gel properties of gelatin from skin of seabass (Lates calcarifer) as influenced by extraction conditions. Food Chem. 152:276-284.

Stainsby, G. 1977. The physical chemistry of gelatin in solution. In: The Science and Technology of Gelatin (Eds. A. G. Ward and A. Courts). Academic Press, London, UK. pp. 315-364

Steel, R. G. D., J. H. Torrie, and D. A. Dickey. 1980. Principles and procedures of statistics: a biometrical approach. MacGraw-Hill, New York, NY, USA.

Taheri, A., A. M. Abedian Kenari, A. Gildberg, and S. Behnam. 2009. Extraction and physicochemical characterization of greater lizardfish (Saurida tumbil) skin and bone gelatin. J. Food Sci. 74:E160-E165. 
Tavakolipour, H. 2011. Extraction and evaluation of gelatin from silver carp waste. World J. Fish Mar. Sci. 3:10-15.

Warmington, B. G. and A. H. Kirton. 1990. Genetic and nongenetic influences on growth and carcass traits of goats. Small Rumin. Res. 3:147-165.
Widyasari, R. and S. Rawdkuen. 2014. Extraction and characterization of gelatin from chicken feet by acid and ultrasound assisted extraction. Food Appl. Biosci. J. 2:83-95.

Yang, H., Y. Wang, P. Zhou, and J. M. Regenstein. 2008. Effects of alkaline and acid pretreatment on the physical properties and nanostructures of the gelatin from channel catfish skins. Food Hydrocoll. 22:1541-1550. 